\title{
glass encodes a site-specific DNA-binding protein that is regulated in response to positional signals in the developing Drosophila eye
}

\author{
Kevin Moses ${ }^{1}$ and Gerald M. Rubin \\ Howard Hughes Medical Institute and Department of Molecular and Cell Biology, University of California, Berkeley, \\ California 94720 USA
}

The glass gene encodes a zinc finger protein required for normal photoreceptor cell development in Drosophila. We show that glass transcripts are present in the third-instar eye-imaginal disc starting in the morphogenetic furrow and extending to the posterior margin of the disc; glass protein is detected in the nuclei of all cells in this region. We also show that glass encodes a site-specific DNA-binding protein. A 27-bp glass-binding site can confer glass-dependent expression on a reporter gene in developing photoreceptor cells, the particular subset of glass-expressing cells known to require glass function. This specificity may represent a regulation of glass protein activity after cells are recruited to the photoreceptor cell fate.

[Key Words: glass; eye development; Drosophila; transcription factor]

Received November 20, 1990; revised version accepted January 15, 1991.

During the development of multicellular organisms, the fate of a cell is often determined by the influence of neighboring cells or tissues. The molecular mechanisms by which such inductive signals cause changes in the genetic program of the responding cell remain largely unknown. In the early stages of the response, signals from the cell surface must lead to modifications in the activity of one or more pre-existing transcription factors, which then set in motion the appropriate cascade of gene activation.

Post-translational activation of transcription factors has been demonstrated in a number of cases, including steroid hormone receptors (Glineur et al. 1990), the yeast heat shock response factor (Sorger and Pelham 1988), and the mammalian factor AP-1 (Angel et al. 1987; Lee et al. 1987). The activation of transcription factors in response to inductive signals during development has proved more difficult to demonstrate, largely because the critical transcription factors have not been identified. Cell identities in the developing eye of Drosophila are determined by induction, and mutations in several genes that encode putative transcription factors have been shown to disrupt normal eye development (for reviews, see Tomlinson 1988; Banerjee and Zipursky 1990). Here, we show that one of these genes, glass, encodes a site-spe-

${ }^{1}$ Present address: Molecular Biology Section, Department of Biological Sciences, University of Southern California, University Park, Los Angeles, California 90089 USA. cific DNA-binding protein and that glass function, in its broadest sense, is regulated at the protein level.

The glass gene is required for the normal development of photoreceptor cells in all three organs in which they occur: the adult compound eye (Johannsen 1924; Garen and Kankel 1983), the adult simple eyes or ocelli (Stark et al. 1984; Moses et al. 1989; Stark and Sapp 1989|, and the larval photoreceptor or Bolwig's organ (Moses et al. 1989|. In the retina, we demonstrated that only the photoreceptor cells have a cell-autonomous requirement for glass function (Moses et al. 1989). Developing glass mutant photoreceptor cells in the eye-imaginal disc express neural antigens and extend axons; however, they show early morphological defects, fail to express the photoreceptor cell-specific protein chaoptin (Ready et al. 1986; Van Vactor et al. 1988; Moses et al. 1989), and die after $\sim 60 \mathrm{hr}$ of pupal development (Ready et al. 1986). We cloned the glass gene and found that it can encode a 604-amino-acid protein with five consecutive $\mathrm{Cys}_{2}-\mathrm{His}_{2}$ zinc finger domains (Moses et al. 1989), suggesting that glass may encode a transcription factor required for the normal development of photoreceptor cells.

Here, we show that the glass protein is expressed in all cell types in the developing eye. However, its ability to activate transcription differs between cell types. In particular, a heterologous promoter construct containing five tandem copies of a glass-binding site can confer glass-dependent expression on a reporter gene in photoreceptor cells in the developing larval eye-imaginal disc. 


\section{Results}

glass expression in the eye-imaginal disc

Given the genetic specificity of glass (Moses et al. 1989), one might expect glass expression to be limited to the photoreceptor cells; however, we found that this is not the case. The photoreceptor cells of the compound eye begin their development in the third-larval instar when a coordinated series of cell shape changes, known as the morphogenetic furrow, progresses across the eye-imaginal disc from posterior to anterior, and in this furrow the first signs of the development of the eye facets for ommatidia) can be seen. Posterior to the furrow, ommatidia are assembled by a process of sequential cell recruitment beginning with the eight photoreceptor cells, followed by the four lens-secreting cone cells and the other accessory cells (Ready et al. 1976; Tomlinson and Ready 1987). These recruitment events are independent of cell lineage (Hotta and Benzer 1970; Ready et al. 1976, Lawrence and Green 1979) and are thought to be mediated by specific instructions that an uncommitted cell receives from its immediate neighbors (Tomlinson 1985; Tomlinson and Ready 1987).

We found that glass RNA is detectable in the eyeimaginal disc beginning in the morphogenetic furrow, where the leading edge of expression is serrated (Fig. 1A,B|. This initial expression pattern appears to be coincident with or closely following the pattern of cells seen in the furrow by cobalt sulfide staining (Tomlinson and Ready 1987). RNA expression is strongest in the furrow and persists at a lower level in more posterior regions of the disc; the resolution of the digoxygenin in situ hybridization method was insufficient to distinguish variations in expression between individual cells. The expression of glass RNA in the furrow is consistent with the onset of the glass mutant phenotype, as some abnor- malities are seen in mutant discs at the earliest stages of ommatidial assembly (Moses et al. 1989). We did not conduct an extensive survey of other tissues and developmental stages; however, other evidence (see below) indicates that glass expression is limited to the visual system and a small number of cells in the central nervous system.

To examine glass protein expression we raised polyclonal sera against three different glass fusion proteins (see Materials and methods), and all produced a similar signal when used to stain imaginal discs. The glass protein is present in the nuclei of all cells posterior to the morphogenetic furrow in the eye-imaginal disc. To establish that the signal was due to specific glass protein detection, discs from a null allele of glass (glass $^{60 ;}$; Moses et al. 1989) were also stained. Thus, we were able to unambiguously distinguish signal from background by directly comparing wild-type to glass-null control discs (Fig. 1C,D). It is intriguing that glass protein is not restricted to the nuclei of the photoreceptor cells, because we have shown previously (Moses et al. 1989) that the accessory cells have no detectable requirement for glass function. These sera do not detect any glass protein in the embryo, larval brain, or the adult head; however, we believe that this negative result is due to the limited sensitivity of these reagents, because we have other evidence (see below) that glass is expressed in these tissues.

To determine whether the glass expression pattern is altered in discs when some cells adopt abnormal fates, we used the anti-glass sera to stain eye-imaginal discs mutant for four genes known to affect eye development: sevenless (Tomlinson and Ready 1986), rough (Tomlinson et al. 1988), scabrous (Mlodzik et al. 1990a; Baker et al. 1990), and Ellipse (Baker and Rubin 1989). None of these mutations affects the progress of the morphogenetic furrow. In all cases, glass protein was detected in
Figure 1. The glass gene is expressed in all cells posterior to the morphogenetic furrow in the eyeimaginal disc. $(A-F)$ Portions of third-instar eyeimaginal discs (magnification, 163 $\times$ ). The arrow in $A$ marks the position of the morphogenetic furrow for $A-F$; posterior is down. $(A$ and $B)$ In situ hybridizations of glass cDNA sequences to wild-type eyeimaginal discs. The specimen in $A$ was developed for a short period to make apparent the high concentration of glass RNA near the furrow. In $B$, glass RNA can be seen to persist to the back of the disc. (C) A wild-type eye-imaginal disc stained with polyclonal anti-glass serum is shown. The nuclei of all cells posterior to the furrow stain. In $D$, a glass ${ }^{60 j}$ eye-imaginal disc stained as in $C$ is shown; glass ${ }^{60}$ is a protein null allele. $(E)$ A genetically glass ${ }^{+}$eye-
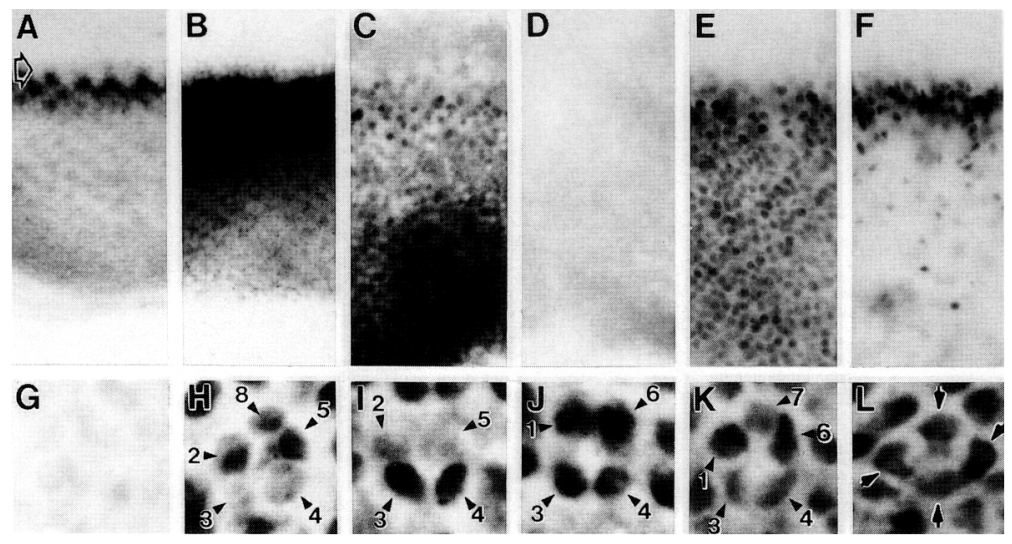

imaginal disc bearing the B172 insertion of the P-lacW element within the glass promoter has been stained with an anti- $\beta$-galactosidase antibody. The nuclei of all cells posterior to the furrow stain. $(F)$ An eye-imaginal disc bearing the B172 insertion in a glass ${ }^{-}\left(\right.$glass $\left.^{B 27}\right)$ genetic background was stained as in $E$. Most nuclei posterior to the morphogenetic furrow do not stain. $(G-L)$ High-power (magnification, $1300 \times$ ) views of individual ommatidia. $(G)$ An ommatidium from the glass ${ }^{60 j}$ eye disc shown in $D$ illustrates the level of nonspecific staining. $(H-L)$ Progressively more mature ommatidia from the disc shown in $C$ are presented; the ommatidium in $L$ is 15 rows behind the furrow (early four-cone cell stage; Tomlinson 1986). Individual photoreceptor cell nuclei are numbered; the arrows in $L$ mark cone cell nuclei. glass can be seen to be expressed in each photoreceptor cell type and the four cone cells. 
the nuclei of all cells posterior to the morphogenetic furrow, although many of these mutants affect the positions and numbers of these nuclei.

\section{glass autoregulation}

We used a lacZ enhancer-trap element $\left\{\mathrm{O}^{\prime} \mathrm{Kane}\right.$ and Gehring 1987; Bellen et al. 1989; Bier et al. 1989) inserted at the glass locus to examine whether glass plays a role in regulating its own transcription. The B172 line carries an insertion of the P-lacW element (Bier et al. 1989) located between 2 and $3 \mathrm{~kb}$ upstream of the start site of glass transcription. In the B172 line $\beta$-galactosidase expression was evident posterior to the furrow (Fig. 1E) and in some cells in the larval brain (data not shown). The pattern of the $\beta$-galactosidase expression in B172 eye-imaginal discs was indistinguishable from that of glass protein. $\beta$-Galactosidase was also expressed in the nuclei of the Bolwig's organ in the late embryo and in some cells of the embryonic and third-instar larval brain (data not shown). No expression was seen in other larval tissues or in the adult head, although glass RNA is detectable in the adult head (Moses et al. 1989).

Because the B172 line reflects the pattern of glass transcription in the eye-imaginal disc, we used the expression of $\beta$-galactosidase in $\mathrm{B} 172$ as a marker to ask if glass protein plays a role in regulating glass expression. To be able to examine expression from the B172 insertion in the absence of glass function, we induced three strong glass alleles on the B172 chromosome using the chemical mutagen ethylmethane sulfonate. We stained the eye-imaginal discs of these alleles with anti- $\beta$-galactosidase antibody in trans both to a null glass allele $\left(\right.$ glass $^{60 i} \mid$ and to a wild-type allele. As glass is fully recessive, we were able to observe the expression pattern of the B172 insertion in both glass ${ }^{+}$and glass ${ }^{-}$genetic backgrounds. All three alleles showed similar results (see Fig. 1F). Although glass mutations affect the morphology of the disc so that identification of individual cell types is difficult, it was clear that B172 lacZ expression in a glass ${ }^{-}$background was greatly reduced or eliminated in most nuclei except for a narrow band near the furrow. In contrast, when heterozygous with a glass ${ }^{+}$ chromosome, expression from the B172 glass ${ }^{-}$chromosome was indistinguishable from that of the parental B172 line. These results suggest that glass protein positively regulates its own expression. Moreover, this regulation occurs in more cells than just the photoreceptors, suggesting that glass protein is also an active transcription factor in nonphotoreceptor cells. In the embryo, the glass mutation greatly reduced or abolished B172 expression in the Bolwig's organs but apparently not in the cells that express B172 in the brain /data not shown). Thus, it appears that glass may have an autoregulatory role in some, but not all, of the cells in which it is expressed.

\section{glass protein binds to specific DNA sequences in vitro}

The glass gene sequence and mutant phenotype suggest that glass protein may directly regulate photoreceptor cell-specific genes. As a test of this hypothesis, we first looked for DNA sequences that are recognized specifically by the glass protein in the promoter of the major rhodopsin gene $(R h 1)$, which is expressed in photoreceptor cells R1-R6 (O'Tousa et al. 1985; Zuker et al. 1985). In glass mutant adults there is no detectable $R h 1$ expression; however, the available data do not address whether this regulation is direct or indirect in vivo. The $R h 1$ promoter has been dissected into three functional sequence elements (Mismer and Rubin 1987, 1989): a fragment containing the core promoter (element III) and two upstream fragments that contain interchangeable enhancer elements (elements I and II). Using a DNase I footprinting assay, we found one 27-bp site bound by bacterially expressed glass protein within the element II fragment and extensive protections over $79 \mathrm{bp}$ in the element I fragment (Fig. 2). Because glass appears to be involved in its own regulation, we also examined an 845 -bp fragment near the $\mathrm{B} 172$ insertion site in the glass promoter that contairs a cluster of sequences similar to that of the $R h 1$ element II site. We found two protected regions extending over 54 and $16 \mathrm{bp}$ (Fig. 2), although the paucity of DNase I cleavage sites in this region makes it difficult to define the precise limits of these binding sites. Although this was not a detailed study, the finding that glass protein can bind to sites within the glass promoter is consistent with a direct role for glass in its own regulation.

glass-binding sites confer glass-dependent regulation on a reporter gene

The observation that glass protein can bind to rhodopsin gene enhancers supports a role for glass in the direct regulation of genes in photoreceptor cells. To demonstrate a function for these sites in vivo we inserted a pentamer of a 38-bp oligonucleotide that includes the 27-bp glass protein-binding site from the $R h 1$ element II enhancer (see Fig. 2) into two different heat shock promoter-lacZ reporter constructs (see Fig. 3A and Materials and methods). In two corresponding control constructs similar oligonucleotides were used, but the $27 \mathrm{bp}$ of the glass-binding site are in a random sequence. Construct A includes the glass-binding site pentamer upstream of a heat shock promoter that is truncated to position $-250 \mathrm{bp}$; this $250 \mathrm{bp}$ is sufficient for heat inducibility. Construct $B$ is the random site control to construct $A$. Construct $C$ is similar to construct $A$, except that the heat shock promoter has been truncated to -50 $\mathrm{bp}$, and construct $\mathrm{D}$ is the random site control to construct C.

Six of the nine independent construct A transformant lines showed a common and striking pattern of $l a c Z$ expression (see Fig. 3E). In the eye-imaginal disc, these lines display a three-zone pattern of expression: no expression anterior to the furrow; weak expression beginning in and just posterior to the furrow; and, finally, strong expression from about the eighth column of developing ommatidia $(\sim 16 \mathrm{hr}$ after the first photoreceptor cell, R8, begins to express neural antigens; Tomlinson and Ready 1987) to the back of the disc. Use of an anti- $\beta$ - 


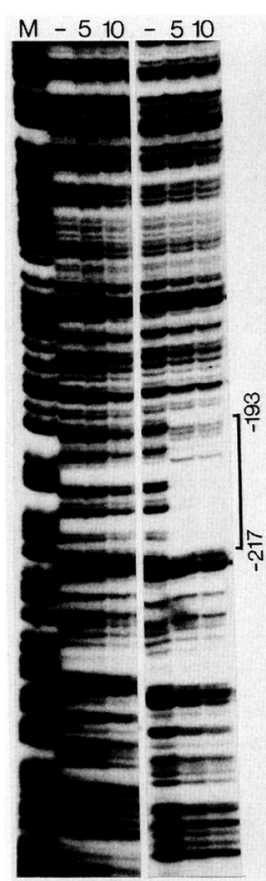

Rh1 enII

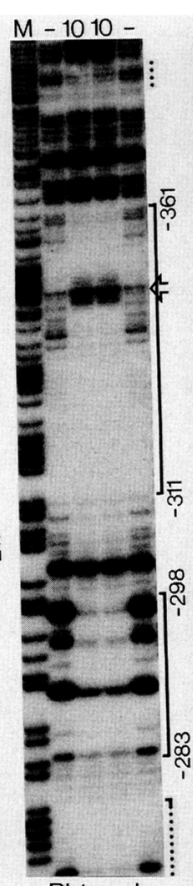

Rh1 enl

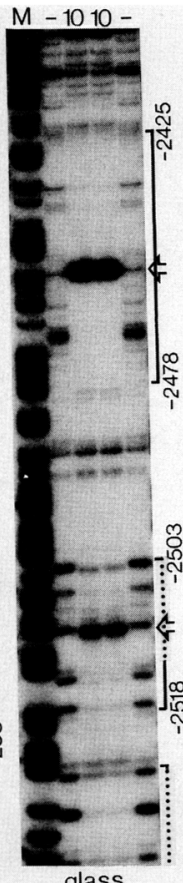

glass

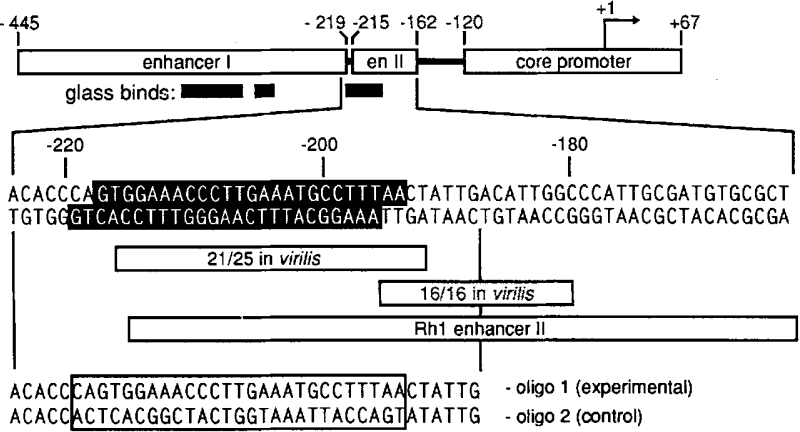

Figure 2. The glass gene encodes a sequence-specific DNA-binding protein. (Left) DNase I protection of sequences from the $R h 1$ and glass promoters, using protein extracts $(3 \mu \mathrm{g} / \mathrm{ml})$ from glassexpressing or control $E$. coli (see Materials and methods). Lanes: $(M)$ Purine cleavage products used as size markers; $|-|$ no extract; $(5$ or 10) the volume (in $\mu$ l) of bacterial extract added. Position numbers are from the start of transcription. (Rh1 enII) DNase I protections of sequences from the $R h 1$ promoter in the region of element II with control (left) and glass-containing extracts (right). ( $R h 1$ enI) DNase I protections of sequences from the $R h 1$ promoter in the region of element I with glass-containing extract. The protected regions seen with the glass-containing extract are indicated by brackets; no specific protection was observed with the control extract. (glass) DNase I protections of sequences from glass genomic DNA with glass-containing extract are shown. (Right) The relationship of glass-protected sequences to features of the structure of the $R h 1$ promoter and their DNA sequence conservation in Drosophila virilis (M. Fuchs and G.M. Rubin, unpubl.). The DNA sequence protected in element II is highlighted. The DNA sequences including the glass-binding site oligonucleotide (experimental), which was based on this protected site, and a corresponding random sequence control oligonucleotide (control), are shown. These oligonucleotides were used to make the glass-binding site pentamer and control pentamer constructs (see Materials and methods).

Figure 3. A glass-binding site pentamer can confer glass-regulated expression on a $\beta$-galactosidase reporter gene in the larval and adult visual systems. $(A)$ A schematic representation of constructs $A$ and $C$. In construct $A$, the glass-binding site pentamer has been inserted $250 \mathrm{bp}$ upstream of the transcriptional start site of a truncated $h s p 70$ promoter driving $1 a c Z$ expression. In construct $\mathrm{C}$, the $h s p 70$ promoter has been truncated to position $-50 \mathrm{bp}$. Two corresponding control constructs were also made in which a pentamer of random sequence, but of the same base composition as the glass-binding site (see Fig. 1), replaced the glass-binding site pentamer; the control constructs corresponding to constructs $\mathrm{A}$ and $\mathrm{C}$ are constructs $\mathrm{B}$ and $\mathrm{D}$, respectively. $(B) \mathrm{A}$ genetically glass ${ }^{+}$larva carrying construct $C$ has been dissected to show the visual system after staining for $\beta$-galactosidase activity (magnification, $80 \times$ ). (b) Bolwig's nerve; (open arrow) the morphogenetic furrow; (os) the optic stalk; (bh) brain hemisphere. $(C)$ The brain hemispheres from a construct $\mathrm{C}$ transformant line in a glass ${ }^{+}$genetic background, stained for $\beta$-galactosidase activity (magnification, $100 \times$ ). The afferent axons from the retina (ax) stain, as do several groups of cell bodies (cb) in the more central brain, which show commissural connections (com) across the midline. $(D)$ The brain hemispheres from the same construct $C$ transformant line shown in $C$, but now in a glass ${ }^{60 i}$ genetic background, have been stained for $\beta$-galactosidase activity (magnification, $100 \times$ ). No staining was observed, indicating that expression of construct $\mathrm{C}$ is glass dependent. $(E-I)$ Portions of eye-imaginal discs (magnification, $250 \times$ ). The morphogenetic furrow is indicated by the arrow, and posterior is down. $(E)$ A disc from a construct $\mathrm{A}$ transformant line in a glass ${ }^{+}$genetic background is shown after staining for $\beta$-galactosidase activity. No staining is seen anterior to the furrow, low-level staining is seen for the first seven rows of developing ommatidia, and then the level of staining greatly increases and extends to the posterior of the disc. $(F)$ A disc from the same construct $\mathrm{A}$ transformant line as shown in $E$ in a glass ${ }^{60}$ genetic background, stained for $\beta$-galactosidase activity. No staining was observed. $(G)$ A disc from a construct $\mathrm{C}$ transformant line in a glass ${ }^{+}$genetic background, stained for $\beta$-galactosidase activity. No staining is seen until the eighth column of developing ommatidia. (H) A disc from the same construct $\mathrm{C}$ transformant line as shown in $G$ in a glass ${ }^{60 i}$ genetic background stained for $\beta$-galactosidase activity. No staining was observed. (I) A disc from the same construct $C$ transformant line as shown in $G$ in a glass ${ }^{+}$genetic background stained with an anti- $\beta$-galactosidase antibody. From the eighth column of developing ommatidia, the photoreceptor cells appear in their normal order of recruitment. The cone cells and basal nuclei do not stain. (J) A section from the head of an adult of a construct $\mathrm{C}$ transformant line in a glass ${ }^{+}$genetic background, stained for $\beta$-galactosidase activity (magnification, $50 \times$ ). Strong staining is seen in the retina (re); the weak staining visible in the lamina (la) most likely is due to $\beta$-galactosidase in the photoreceptor axons. $(K)$ A section from the head of an untransformed glass ${ }^{+}$adult stained as in $J$. No staining is seen. $(L)$ An apical adult head section of the same construct $C$ transformant line stained for $\beta$-galactosidase activity (magnification, $100 \times$ ). Staining is seen in the ocelli (asterisks). (M) An apical section from the head of an untransformed glass ${ }^{+}$adult stained as in $J$. No staining is seen in the ocelli (asterisks). Staining for $\beta$-galactosidase activity was carried out as described in Materials and methods; the stainings shown in $C, D, G$, and $H$ were carried out in the presence of SDS. 

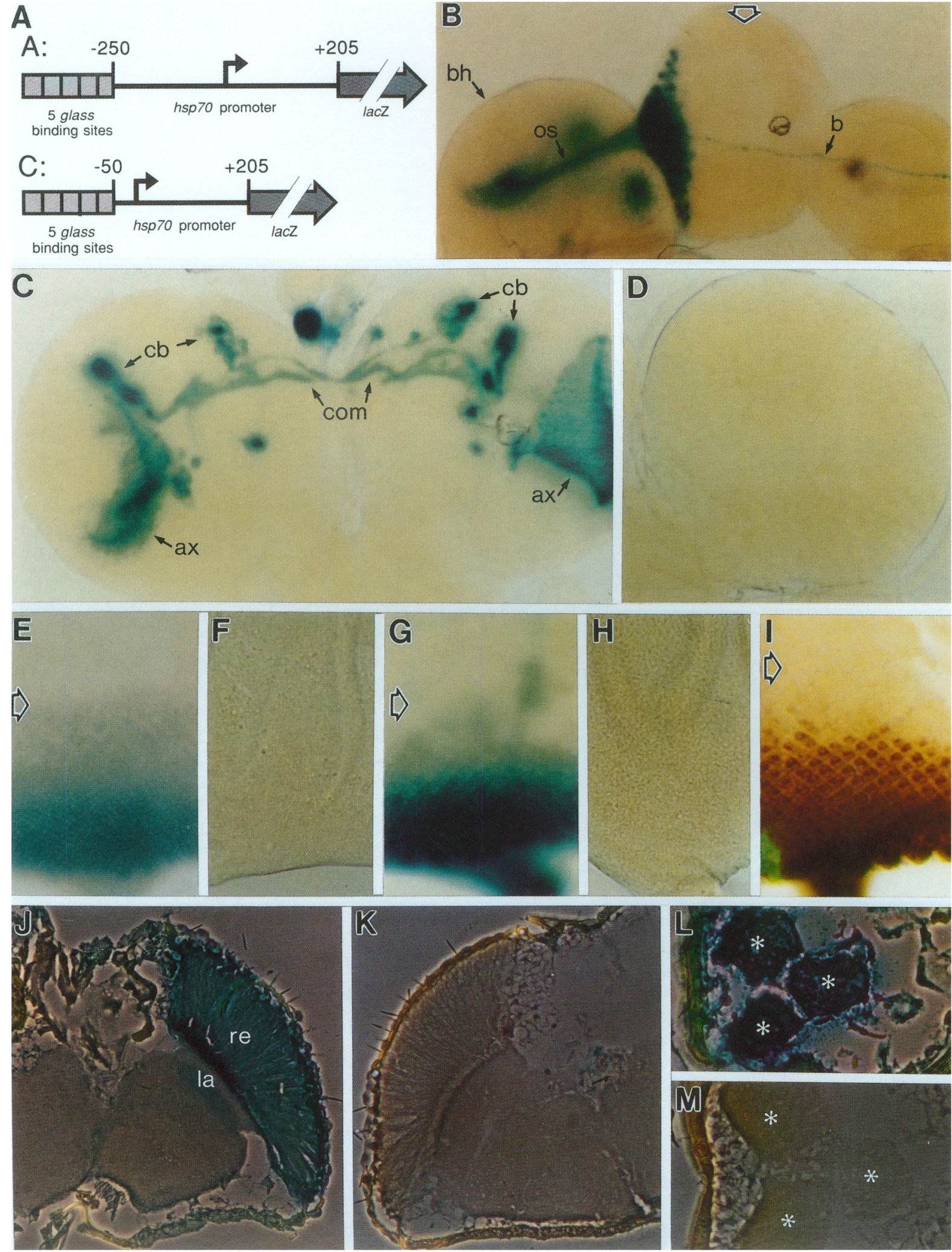

Figure 3. (See facing page for legend.) 
galactosidase antibody showed that this high-level expression is only in photoreceptor cells and that they initiate this expression in the same order as that in which they express neural antigens (see Fig. 4). No such staining is seen in the cone cells, although they express high levels of glass protein. The early low-level expression is more diffuse and may be in all cells. To determine whether this pattern of expression is regulated by glass, three of these lines were crossed into a glass mutant genetic background. In all three lines, $\beta$-galactosidase expression was abolished, suggesting that the pattern was generated by the binding of the glass protein to the pentamer site in vivo (Fig. 3F). The other three construct $A$ lines showed patterns that may be most simply interpreted as chromosome position effects on the inserted construct; in the one example tested in a glass mutant background, the expression pattern was unaffected, indicating that this pattern is not controlled by glass. Similarly, seven independent lines were recovered for construct $B$, the random site control to construct $A$; of these, three were tested in a glass mutant background. Various weak expression patterns were observed in the third-larval instar eye-imaginal discs and brain; none of these patterns are glass dependent.

Ten independent construct $C$ lines showed a much stronger and more tightly restricted expression pattern than those of construct A (Fig. 3, B, G, and I). No expression was seen anterior to the furrow or in the first seven rows of developing ommatidia, but intense staining was seen in the posterior part of the disc where it was restricted to the photoreceptor cells. As for construct A, staining appeared in the normal sequence of photoreceptor cell recruitment (see Fig. 4) and was absent from the cone cells. This expression was abolished in all four lines tested in a glass mutant background (Fig. $3 \mathrm{H}$ ). Eight independent lines were recovered for construct $D$, the random site control for construct $C$; of these, six were tested in a glass mutant background. Although all eight showed strong and widespread lac $Z$ expression in the larva, including both anterior and posterior to the furrow in the eye-imaginal disc, no part of this $l a c Z$ expression pattern was glass dependent.

In the third-instar larval brain, all 10 construct $C$ lines showed strong staining in the photoreceptor cell axons and also in several groups of cell bodies deeper in the brain. In these cells, the stain permeated the cytoplasm and revealed that their axons form commissural paths crossing the midline (Fig. $3 \mathrm{C}$ ). All of this staining was glass dependent (Fig. 3D), and the positions of the lacZexpressing cells in the brain are consistent with the positions of cells that weakly stain in the enhancer trap line B172. These data support a role for glass in the regulation of gene expression in the developing brain as well as in the retina. In the embryo, constructs $\mathrm{A}$ and $\mathrm{C}$ showed similar patterns of glass-dependent staining; as in the eye disc, construct $\mathrm{C}$ displayed more intense staining (Fig. 5). With this intense expression, the Bolwig's nerve can be traced for its entire length, from the cell bodies to the growth cone; this can be seen just above a small group of the cells that stain in the brain, which may include the optic lobe precursor cells (Tix et al. 1989). A similar but less intense staining was seen in B172 embryos. In the adult head, both constructs are expressed in the retinas and the ocelli but not in the brain (construct $\mathrm{C}$ is shown in Fig. 3J,L). However, unlike for the larva, for the adult, a glass mutant control is not informative because in glass $^{-}$adults the retina, ocelli, and brain are degenerate.

glass function, but not expression, is downstream of sevenless in the $R 7$ cell alone

That glass function is activated in the photoreceptors and not the cone cells implies that this activation is downstream of the signals and receptors that mediate photoreceptor cell recruitment. The sevenless mutation prevents the presumptive $\mathrm{R} 7$ cell from developing as a photoreceptor by blocking an incoming inductive signal at the cell surface; therefore, we might expect this mutation to block the activation of glass in this cell. We stained sevenless eye-imaginal discs with the glass antibody and found the pattern of glass protein expression to be unaltered. We also crossed a construct $\mathrm{A}$ and a construct $C$ line into a sevenless background and stained the eye-imaginal discs for $\beta$-galactosidase antigen. In both cases, the pattern was the same as in sevenless ${ }^{+}$, with the exception of the presumptive $R 7$ cells, in which the reporter was silent (see Fig. 4K,L). This result implies that although the expression of glass protein is unaffected by sevenless, the function of the glass protein is affected specifically in the presumptive $\mathrm{R} 7$ cell.

\section{Discussion}

We reported previously that the glass gene encodes a zinc finger protein that is required for photoreceptor cell development (Moses et al. 1989). Here, we show that glass protein can bind in vitro to specific enhancer sequences from the $R h 1$ rhodopsin gene, as well as to the promoter of the glass gene itself. glass RNA is expressed posterior to the morphogenetic furrow in the developing eye-imaginal disc, and glass protein shows a parallel distribution, being found in the nuclei of all cells posterior to the furrow. A high level of glass RNA is observed in the morphogenetic furrow; glass shares this early and general expression pattern with the rough gene (Kimmel et al. 1990|, and both genes may be responding to similar cues. We identified a $l a c Z$ enhancer trap insertion close to glass, B172, that accurately mimics the glass antibody pattern in the eye disc and reveals sites of expression in the larval visual system and brain. Moreover, aspects of the B172 expression pattern are glass dependent, suggesting that glass plays a role in its own regulation. Our data also reveal a novel function for glass in the activation of gene expression in a few cells of the embryonic and larval brain. The identity and function of these cells is unknown. However, there is evidence indicating that the brain can detect light by a mechanism independent of 


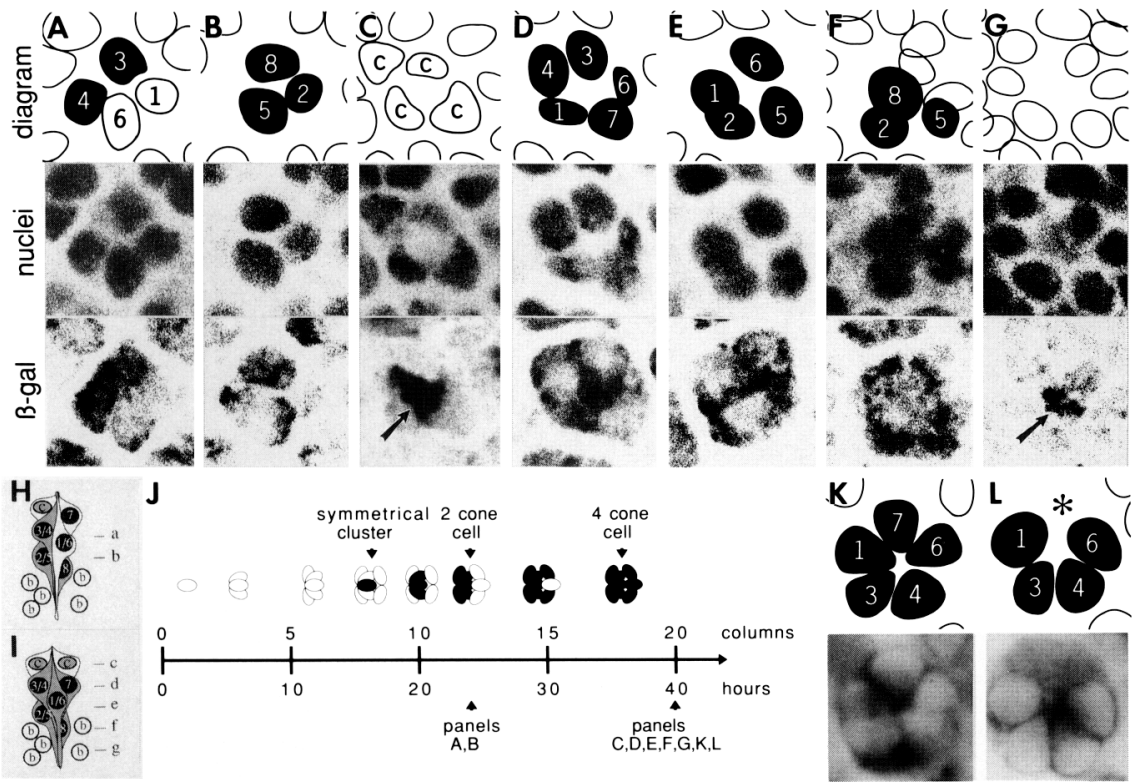

Figure 4. glass functional modulation follows photoreceptor-cell recruitment. $(A-G)$ Confocal images of two different developing ommatidia from a larva carrying construct A (magnification, 2050×), which have been stained with the DNA-binding compound chromomycin A3 to reveal all nuclei and with anti- $\beta$-galactosidase antibody to reveal expression of the construct A reporter gene. The upper third of each panel shows a diagram of the positions of the cell nuclei observed in that optical section; the central third shows nuclear fluorescence; the lower third shows the same field and plane of focus stained for $\beta$-galactosidase expression (see Materials and methods). Each diagram shows the nuclei of those cells outside the ommatidium of interest as unshaded, and the nuclei of those cells in this ommatidium as either shaded gray (if the cell is not expressing high levels of $\beta$-galactosidase) or black (if the cell is expressing high levels of $\beta$-galac-

tosidase). $(A$ and $B)$ A two-cone cell stage ommatidium from column 12 (see diagram in $J$; Tomlinson and Ready 1987). The section in $A$ lies $2 \mu \mathrm{m}$ distal to that in $B$, as diagramed in $H$. At this stage, photoreceptors $\mathrm{R} 8, \mathrm{R} 2, \mathrm{R} 5, \mathrm{R} 3$, and $\mathrm{R} 4$ are expressing high levels of $\beta$-galactosidase, and R1 and R6 are just beginning to do so. $(C-G)$ Consecutive $2-\mu \mathrm{m}$ confocal sections (see diagram in $I$ ) through a four-cone cell stage ommatidium from column 20 (Tomlinson and Ready 1987). At this stage, all of the photoreceptor cells express high levels of $\beta$-galactosidase, whereas no $\beta$-galactosidase is detected in the cone cells. The area of $\beta$-galactosidase staining in the lower part of $C$ (arrow) corresponds to the apical cytoplasm of the photoreceptor cells as they project between the cone cell nuclei. In $G$, the nuclei of only the basal cells are visible (circles labeled b in $H$ and $I$ ); these cells are uncommitted precursors and do not express high levels of $\beta$-galactosidase. However, the axons projecting down from the photoreceptor cell bodies (arrow) contain $\beta$-galactosidase. ( $/$ ) A diagram summarizing these data. Photoreceptor cells are shown as they are assembled into the ommatidia: R8, R8/R2/R5, R8/ $\mathrm{R} 2 / \mathrm{R} 5 / \mathrm{R} 3 / \mathrm{R} 4, \mathrm{R} 8 / \mathrm{R} 2 / \mathrm{R} 5 / \mathrm{R} 3 / \mathrm{R} 4 / \mathrm{R} 1 / \mathrm{R} 6$ and, finally, all eight photoreceptors, R1-R8. Developmental time is indicated as hours following the passage of the morphogenetic furrow or as the number of columns behind the furrow. The symmetrical cluster, two-cone cell, and four-cone cell stages (Tomlinson 1985) are indicated. The cells are shown as unshaded from the time at which they first express the neural antigen recognized by mAb 22C10 (Tomlinson and Ready 1987) and as solid from the time at which they first express high levels of $\beta$-galactosidase from construct $\mathrm{A}$. $(K$ and $L)$ Ommatidia from column 20 in late third-instar eye-imaginal discs (the four-cone cell stage) of a construct $C$ transformant line, stained with an anti- $\beta$-galactosidase antibody, visualized with $D A B$

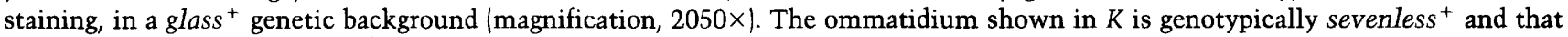
in $L$ is genotypically sevenless ${ }^{d 2}$. In $K$, the nuclei of photoreceptor cells $1,3,4,6$, and 7 are made visible by the intense cytoplasmic stain. In $L$, at the same focal plane, the nucleus of the $\mathrm{R} 7$ cell is not seen (its normal position is marked by the asterisk). In the sevenless mutation, the R7 cell is transformed into a non-neuronal cone cell (Tomlinson and Ready 1986). The cone cells are not visible in this plane of focus; however, no $\beta$-galactosidase expression was observed in the cone cells in either sevenless ${ }^{+}$or sevenless $^{d 2}$ ommatidia.

the known photoreceptors (e.g., see Dushay et al. 1989), and it is possible that these glass-expressing cells are involved in this process.

We have shown that glass protein distribution and glass functional activity are not coincident and that in certain promoter constructs glass function is observed only in photoreceptor cells. A pentamer of the glassbinding site from an $R h 1$ enhancer confers glass-dependent expression on a heat shock-lacZ reporter gene in two different constructs in vivo in the developing compound eye. The differences in $\beta$-galactosidase expression pattern between the two heat shock-lacZ reporter genes may reflect differences in the context or length of the promoters, which affect their sensitivity to different functional states of the glass protein. Indeed, the Rh1 gene from which the glass-binding site was obtained is not active at all in the eye disc. Clearly, natural promoters are more complex in their regulation than our artifi- cial constructs and may reflect the interplay of many different transcription factors. However, constructs A and $\mathrm{C}$ provide an in vivo assay that allows us to distinguish between states of glass function in isolation from the effects of other factors that may act on natural promoters.

Beginning in the morphogenetic furrow, glass protein is expressed in all cells; glass appears to be able to positively regulate its own promoter and is required to induce the low-level expression of construct $A$ seen in the first seven rows of developing ommatidia. In addition, ommatidial development is abnormal in glass mutants even at these very early stages (Moses et al. 1989). Thus, the glass protein appears to be an active transcription factor in the first seven rows of developing ommatidia yet is unable to activate more stringent promoters such as that of construct $C$. From about the eighth column of developing ommatidia $(\sim 16 \mathrm{hr}$ after the first photorecep- 


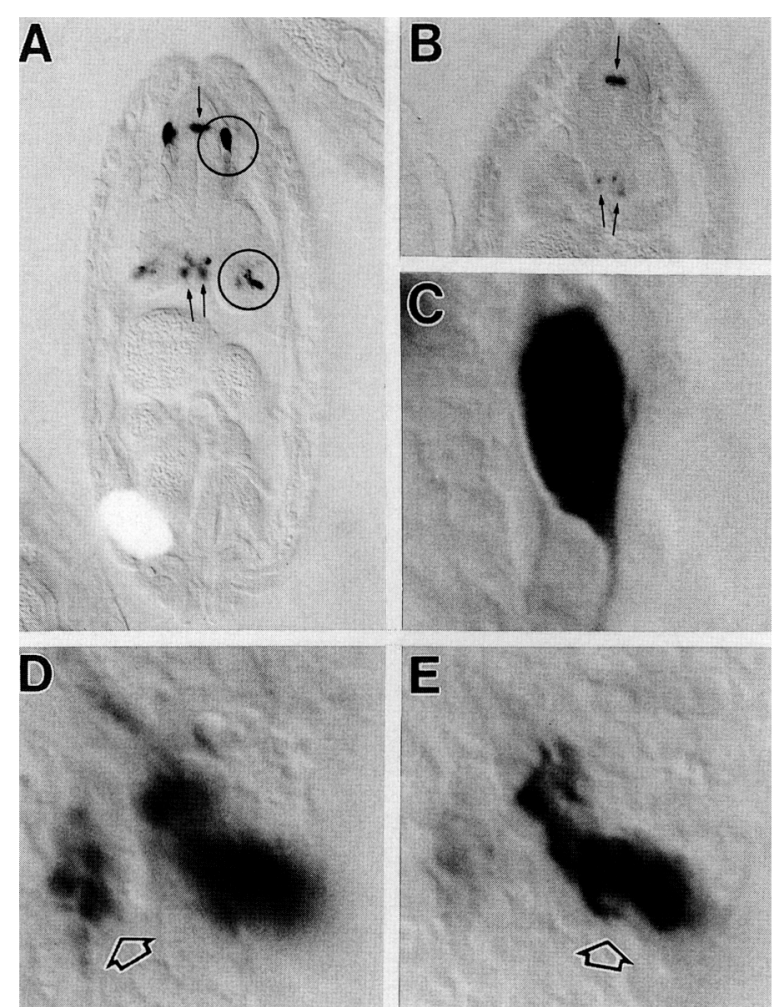

Figure 5. A glass-binding site pentamer can confer glass-regulated expression on a $\beta$-galactosidase reporter gene in the embryonic nervous system. A late embryo of a construct $C$ transformant line in a glass ${ }^{+}(A)$ or glass $^{-}(B)$ genetic background is shown after staining with an anti- $\beta$-galactosidase antibody (magnification, $75 \times$ ). In a glass ${ }^{+}$background $(A)$ staining is seen in the Bolwig's organs (upper circle), the Bolwig's nerve growth cone and a small group of cells in the brain hemispheres (lower circle), and two central structures (arrows). Unlike the other observed staining, the staining in these central structures is not glass-dependent as they remain stained when this transformant line is crossed into a glass ${ }^{601}$ genetic background $(B)$. (C) A highmagnification view $(750 \times)$ of the Bolwig's organ circled in $A$. (D and E) Two planes of focus of the same area showing highmagnification views $(750 \times)$ of two groups of cells in the brain hemisphere (arrows).

tor cells express neural antigens) glass is capable of activating the photoreceptor-specific promoter of construct $\mathrm{C}$ and the high-level photoreceptor-specific expression of construct $\mathrm{A}$. The expression of construct $\mathrm{C}$ closely resembles that of the chaoptin gene, a glass-dependent gene (Moses et al. 1989) that is the earliest gene known to be expressed specifically in photoreceptors (Zipursky et al. 1984). There is no apparent increase in the levels of glass protein in photoreceptors from column eight, implying that this functional change occurs post-translationally.

An early step in the modification of the developmental program of a target cell by an inductive signal must be the activation of one or more pre-existing transcription factors. However, it has been possible to demonstrate the post-translational activation of a particular factor in few developing systems. One such example is the Drosophila dorsal protein, which becomes localized to the nucleus in response to inductive signals in the ventral part of the developing embryo (for review, see Gilmore 1990). dorsal has recently been shown to be related to the mammalian factor NF- $\mathrm{kB}$, which can be released from a cytoplasmic inhibitor by various extracellular signals, move to the nucleus, and act as a transcription factor (for review, see Lenardo and Baltimore 1989). The change in function of the glass protein that we observe does not involve any apparent change in its subcellular localization as it is already present in the nucleus. Thus, any modulation of glass protein function in photoreceptor cells must operate by a different mechanism.

Our results do not allow us to determine whether modulation of glass function results from a change in binding or a difference in the activity of the bound factor. Nor do they address the molecular nature of the modulating mechanism or clarify whether the glass protein itself or the level or activity of a coactivator protein is altered. Moreover, we cannot rule out the possibility that another factor acts on the glass DNA-binding sites, but our data show that the presence or activity of such a factor would itself then have to be dependent on glass function because the change in the activity mediated by the DNA-binding sites is under the genetic control of the glass gene.

Although glass function is required in all of the photoreceptor cell subtypes, the extracellular signals leading to its functional modulation may differ in each. Indeed, glass may be the point at which these signals converge, leading to the initiation of those aspects of cellular development common to all photoreceptors. An understanding of the mechanism(s) by which the function of the glass protein is controlled may lead to a wider understanding of the ways in which transcription factors respond to intra- and intercellular signals during development.

\section{Materials and methods}

Drosophila stocks

Wild-type Canton-S flies were used. The transformation recipient was rosy $y^{506}$. The glass alleles used were $g 1^{1}, g 1^{2}, g 1^{3}$ $\mathrm{T}(2 ; 3) g 1^{63 d 29}$, and $g 1^{60 i}$ (Moses et al. 1989). The last two were found to be protein nulls, and $g 1^{60 i}$ was used as the null allele in all experiments. Other mutations used were sevenless ${ }^{d 2}$ (Banerjee et al. 1987), rough ${ }^{X 63}$ (Kimmel et al. 1990), scabrous ${ }^{1}$ (Baker et al. 1990; Mlodzik et al. 1990a), and Ellipse ${ }^{1}$ (Baker and Rubin 1989|. Chromosomes bearing an insertion of constructs A-D were either balanced (for the lethals and steriles) or made homozygous. Insertions on the $\mathrm{X}$ or second chromosomes were introduced into a glass mutant background by means of standard crosses. The position of insertion in the enhancer trap line B172 was determined by genomic DNA blots to lie between 3148 and 2068 bp $5^{\prime}$ to the start of glass transcription.

\section{DNA-binding assays}

The cDNA clone 5A6 (Moses et al. 1989) was mutated in vitro to introduce an NdeI site at the $5^{\prime}$ end of the glass open reading 
frame. A 2056-bp fragment from this NdeI site to a BamHI site in the $3^{\prime}$-untranslated region was inserted between the NdeI and BamHI sites of pAR3038 (Rosenberg et al. 1987). glass protein was expressed from this plasmid in Escherichia coli strain BL21 DE3 (Studier and Moffatt 1986) after IPTG induction. The protein was recovered from the bacteria as described by Hoey et al. (1988). The protein was found to be highly insoluble and was partially solubilized by treatment with $4 \mathrm{M}$ urea followed by slow dialysis. This glass protein migrates as $62 \mathrm{kD}$ on an SDSPAGE gel, consistent with the size predicted from the cDNA sequence, and its final concentration was $\sim 3 \mu \mathrm{g} / \mathrm{ml}$. A parallel preparation was made from cells containing the vector pAR3038 with no glass-coding insert for use as a negative control.

DNase I protection reactions were carried out as described by Heberlein and Tjian (1988), in a total reaction volume of $50 \mu \mathrm{l}$ with no competitor or with $40 \mu \mathrm{g} / \mathrm{ml}$ of sonicated calf thymus DNA or $400 \mu \mathrm{g} / \mathrm{ml}$ of poly[d(I-C)]. The DNA substrates for the $R h 1$ elements II and III were a 319-bp fragment from the subclone pP[ry; Rh1 $(-252 /+67)-C A T]$ (Mismer and Rubin 1987), labeled at the left-flanking NotI site and recut with $K p n I$ for the coding strand or the right-flanking NotI site and recut with $\mathrm{XbaI}$ for the noncoding strand. The DNA substrate for the $R h 1$ element I region was a 282-bp XhoI-BamHI fragment from $\mathrm{pP}[\mathrm{ry}$; $R h 1 \mid-162 /+67)-C A T-R h 1 \mid-501 /-219)]$ (Mismer and Rubin 1987), labeled at the BamHI site for the coding strand and the $X$ ol site for the noncoding strand. The DNA substrate from the glass gene was an 845-bp Nael (position 1626 in the glass genomic sequence, accession number $\mathrm{X} 15400$ ) to ClaI (position 2471) fragment inserted into the vector pBluescript KS M131+1 (Stratagene) between the EcoRV and the ClaI sites. This fragment was excised by cutting with $X$ hoI and $B a m H I$ and labeled at the $X$ hoI site for the coding strand and at the BamHI site for the noncoding strand.

\section{In situ hybridization, histochemistry, and immunocytochemistry}

In situ hybridization to imaginal discs was performed as described by Tautz and Pfeifle (1989), as modified by Mlodzik et al. (1990b). The probe was the glass cDNA 5A6. The glass protein was localized by the use of murine polyclonal antisera raised against trpE-glass fusion proteins and goat anti-mouse secondary antibody conjugated to horseradish peroxidase $(1: 200$, Bio$\mathrm{Rad}$ ). Three fusion proteins were generated and expressed in $E$. coli strain HB101. These proteins consisted of the following segments of the glass protein joined to the carboxyl terminus of the $37-\mathrm{kD} \operatorname{trpE}$ fragment encoded by the expression vector pATH11 (a gift of T.J. Koerner and A. Tzagoloff): amino acids 1-604 (the entire glass protein), amino acids $1-438$, or amino acids 86-604. The 86-604 serum is shown in Figure 1. All three $\operatorname{trp} E$ fusion proteins were expressed in E. coli strain $\mathrm{HB} 101$ and purified by electroelution from SDS-PAGE gels. Mice of the strains BALB/c and Swiss/Webster were injected subcutaneously with $50 \mu \mathrm{g}$ of the antigens in Freund's complete adjuvant and given boosts of $25 \mu \mathrm{g}$ of the antigens in Freund's incomplete adjuvant at 2-week intervals. Mice were bled from the tail vein 10 days after each secondary boost, and the resulting sera were used to stain eye-imaginal discs as described by Tomlinson and Ready (1987).

$\beta$-Galactosidase activity was detected in adult head sections as described by Mlodzik et al. (1990b) and in larval tissues by fixation in $1 \%$ gluteraldehyde in $0.1 \mathrm{M}$ sodium phosphate buffer (pH 7.4) for 15-30 min, followed by two 5-min washes in $0.1 \mathrm{M}$ sodium phosphate buffer ( $\mathrm{pH} 7.4)$. After incubation overnight in the staining solution of Simon et al. (1985), tissues were washed in $0.1 \mathrm{M}$ sodium phosphate buffer $(\mathrm{pH} 7.4)$ and mounted in $80 \%$ glycerol. Strongly staining lines (constructs $\mathrm{C}$ and D) were stained using a variation of this protocol (Fire et al. 1990; as modified by $U$. Gaul, pers. comm.), substituting an activity stain composed of $0.1 \mathrm{M}$ sodium phosphate buffer ( $\mathrm{pH} 7.4), 1 \mathrm{mM}$ $\mathrm{MgCl}_{2}, 10 \mathrm{mM} \mathrm{K}_{3} \mathrm{Fe}(\mathrm{CN})_{6}, 10 \mathrm{mM} \mathrm{K}_{4} \mathrm{Fe}(\mathrm{CN})_{6}, 0.004 \%$ SDS, and $2.67 \% \mathrm{X}$-gal. The use of SDS significantly reduces the sensitivity of the reaction but greatly increases the penetration of the stain, allowing superior localization of $\beta$-galactosidase activity in the brain. $\beta$-Galactosidase protein was localized immunologically in eye-imaginal discs as described by Mlodzik et al. $(1990 \mathrm{~b})$ and in embryos by a minor modification to the protocol described by Mitchison and Sedat (1983).

For fluorescence microscopy, $\beta$-galactosidase was detected as described by Mlodzik et al. (1990b), except that a goat antimouse antibody coupled to Texas Red (Jackson ImmunoResearch/ was used as the secondary antibody. Nuclei were detected by staining with chromomycin A3 (Sigma), as described by Foe (1989). Preparations were mounted in $85 \%$ glycerol plus $2.5 \%$ propyl gallate and photographed using a Bio-Rad confocal microscope.

\section{Drosophila transformation}

We used four oligonucleotides to produce double-stranded DNA fragments of the sequences shown in Figure 1, with a Sall site on the $5^{\prime}$ end and an XhoI site at the $3^{\prime}$ end, such that the annealed pairs of oligonucleotides have TCGA $5^{\prime}$ single-strand extensions. The sequences of the four oligonucleotides are as follows:

1. 5'-TCGAGACACCCAGTGGAAACCCTTGAAATGCCTTTAACTATTG-3'
2. 5'-TCGACAATAGTTAAAGGCATTTCAAGGGT TTCCACTGGGTGTC-3'
3. 5'-TCGAGACACCACTCACGGCTACTGGTAAATTACCAGTATATTG-3'
4. 5'-TCGACAATATACTGGTAATTTACCAGT AGCCGTGAGTGGTGTC-3'

The oligonucleotides were end-labeled by treatment with T4 polynucleotide kinase and $\left[\gamma^{32} \mathrm{P}\right] \mathrm{ATP}$. Oligo 1 was annealed to oligo 2 to produce a double-stranded fragment including a glass protein-binding site, and oligo 3 was annealed to oligo 4 to produce a double-stranded fragment without a glass protein-binding site. Each fragment type was then ligated to form concatamers in the presence of both SalI and Xhol restriction enzymes. The ligation products were run on a nondenaturing acrylamide gel, and the pentamers were eluted and inserted into the vector pBluescript KS M13/ + | (Stratagene) between the XhoI and SalI sites. Clones were selected that had inserted in the orientation that restores both the XhoI and SalI sites, and the head-tail pentamer structure was confirmed by sequencing. The glassbinding site and control pentamers were then cloned into the XhoI site of the kanamycin-resistant NotI shuttle vector pHSX (a gift of K. Jones) and then as NotI fragments into the NotI site of the P-element transformation vectors pDM30hslacZ (Bowtell et al. 1989) to generate constructs A and B, and into HZ50PL (Hiromi and Gehring 1987) to generate constructs $C$ and D. In each case, the orientation of the pentamer was confirmed by DNA sequencing to be in the same orientation relative to transcription as this sequence is in the natural $R h 1$ promoter (Mismer and Rubin 1987). rosy ${ }^{506}$ embryos were injected with 1.2 $\mathrm{mg} / \mathrm{ml}$ of construct and $0.4 \mathrm{mg} / \mathrm{ml}$ of helper plasmid (pUChs $\Pi \Delta 2-3 \mathrm{wc}$ ), and G1-transformed flies were selected on the basis of their rosy ${ }^{+}$phenotype (Rubin and Spradling 1982).

\section{Acknowledgments}

We thank Mike Ellis for much support and assistance, Marek Mlodzik for assistance with the in situ hybridizations, Donna 
Nakahara and Tom Lila for the original isolation of B172, David Bowtell, Yash Hiromi, and Kevin Jones for the gifts of plasmid vectors, Ulrike Gaul for her help with and modifications to the activity staining protocol, and Tian $\mathrm{Xu}$ for his help with the operation of the confocal microscope. This work was supported by National Institutes of Health grant GM33135 to G.M.R. K.M. was supported by the American Cancer Society, California Division, Inc., as the Caroline Spitzer fellow.

The publication costs of this article were defrayed in part by payment of page charges. This article must therefore be hereby marked "advertisement" in accordance with 18 USC section 1734 solely to indicate this fact.

\section{References}

Angel, P., M. Imagawa, R. Chiu, B. Stein, R.J. Imbra, H.J. Rahmsdorf, C. Jonat, P. Herrlich, and M. Karin. 1987. Phorbol ester-inducible genes contain a common cis element recognized by a TPA-modulated trans-acting factor. Cell 49: 729-739.

Baker, N.E. and G.M. Rubin. 1989. Effect on eye development of dominant mutations in Drosophila homologue of the EGF receptor. Nature 340: 150-153.

Baker, N.E., M. Mlodzik, and G.M. Rubin. 1990. Spacing differentiation in the developing Drosophila eye: A fibrinogenrelated lateral inhibitor encoded by scabrous. Science 250: $1370-1377$.

Banerjee, U. and S.L. Zipursky. 1990. The role of cell-cell interaction in the development of the Drosophila visual system. Neuron 4: 177-187.

Banerjee, U., P.J. Renfranz, J.A. Pollock, and S. Benzer. 1987. Molecular characterization and expression of sevenless, a gene involved in neuronal pattern formation in the Drosophila eye. Cell 49: 281-291.

Bellen, H.J., C.J. O'Kane, C. Wilson, U. Grossniklaus, R.K. Pearson, and W.J. Gehring. 1989. P-element mediated enhancer detection: A versatile method to study development in Drosophila. Genes ef Dev. 3: 1288-1300.

Bier, E., H. Vaessin, S. Shephard, K. Lee, K. McCall, S. Barbel, L. Ackerman, R. Carretto, T. Uemura, E. Grell, L.Y. Jan, and Y.N. Jan. 1989. Searching for pattern and mutation in the Drosophila genome with a P-lacZ vector. Genes et Dev. 3: $1273-1287$.

Bowtell, D.D.L., B.E. Kimmel, M.A. Simon, and G.M. Rubin. 1989. Regulation of the complex pattern of sevenless expression in the developing Drosophila eye. Proc. Natl. Acad. Sci. 86: 6245-6249.

Dushay, M.S., M. Rosbash, and J.C. Hall. 1989. The disconnected visual system mutations in Drosophila melanogaster drastically disrupt circadian rhythms. J. Biol. Rhythms 4: 127.

Fire, A., S.W. Harrison, and D. Dixon. 1990. A modular set of lac- $Z$ fusion vectors for studying gene expression in Caenorhabditis elegans. Gene 93: 189-198.

Foe, V.E. 1989. Mitotic domains reveal early commitment of cells in Drosophila embryos. Development 107: 1-22.

Garen, S.H. and D.R. Kankel. 1983. Golgi and genetic mosaic analyses of visual system mutants in Drosophila melanogaster. Dev. Biol. 96: 445-466.

Gilmore, T.D. 1990. NF- $\mathrm{kB}, \mathrm{KBF} 1$, dorsal, and related matters. Cell 62: 841-843.

Glineur, C., M. Zenke, H. Bueg, and J. Ghysdael. 1990. Phosphorylation of the v-erbA protein is required for its function as an oncogene. Genes $\Leftrightarrow$ Dev. 4: 1663-1676.

Heberlein, U. and R. Tjian. 1988. Temporal pattern of alcohol dehydrogenase gene transcription reproduced by Drosophila stage-specific embryonic extracts. Nature 331: 410-415.

Hiromi, Y. and W.J. Gehring. 1987. Regulation and function of the Drosophila segmentation gene fushi tarazu. Cell 50: $963-974$.

Hoey, T., R. Warrior, J. Manak, and M. Levine. 1988. DNAbinding activities of the Drosophila melanogaster evenskipped protein are mediated by its homeo domain and influenced by protein context. Mol. Cell. Biol. 8: 4598-4607.

Hotta, Y. and S. Benzer. 1970. Genetic dissection of the Drosophila nervous system by means of mosaics. Proc. Natl. Acad. Sci. 67: 1156-1163.

Johannsen, O.A. 1924. Eye structure in normal and eye mutant Drosophilas. J. Morphol. 39: 337-349.

Kimmel, B.E., U. Heberlein, and G.M. Rubin. 1990. The homeo domain protein rough is expressed in a subset of cells in the developing Drosophila eye where it can specify photoreceptor cell subtype. Genes $\Theta$ Dev. 4: 712-727.

Lawrence, P.A. and S.M. Green. 1979. Cell lineage in the developing retina of Drosophila. Dev. Biol. 71: 142-152.

Lee, W., P. Mitchell, and R. Tjian. 1987. Purified transcription factor AP-1 interacts with TPA-inducible enhancer elements. Cell 49: 741-752.

Lenardo, M.J. and D. Baltimore. 1989. NF-кB: A pleiotropic mediator of inducible and tissue-specific gene control. Cell 58: 227-229.

Mismer, D. and G.M. Rubin. 1987. Analysis of the promoter of the ninaE opsin gene in Drosophila melanogaster. Genetics 116: $565-578$.

- 1989. Definition of cis-acting elements regulating expression of the Drosophila melanogaster ninaE opsin gene by oligonucleotide-directed mutagenesis. Genetics 121: 7787.

Mitchison, T.J. and J. Sedat. 1983. Localization of antigenic determinants in whole Drosophila embryos. Dev. Biol. 99: 261-264.

Mlodzik, M., N.E. Baker, and G.M. Rubin. 1990a. Isolation and expression of scabrous, a gene regulating neurogenesis in Drosophila. Genes \& Dev. 4: 1848-1861.

Mlodzik, M., Y. Hiromi, U. Weber, C.S. Goodman, and G.M. Rubin. 1990b. The Drosophila seven-up gene, a member of the steroid receptor gene superfamily, controls photoreceptor cell fates. Cell 60: 211-224.

Moses, K., M.C. Ellis, and G.M. Rubin. 1989. The glass gene encodes a zinc-finger protein required by Drosophila photoreceptor cells. Nature 340: 531-536.

O'Kane, C.J. and W.J. Gehring. 1987. Detection in situ of genomic regulatory elements in Drosophila. Proc. Natl. Acad. Sci. 84: 9123-9127.

O'Tousa, J.E., W. Baehr, R.L. Martin, J. Hirsh, W.L. Pak, and M.L. Applebury. 1985. The Drosophila ninaE gene encodes an opsin. Cell 40: 839-850.

Ready, D.F., T.E. Hanson, and S. Benzer. 1976. Development of the Drosophila retina, a neurocrystalline lattice. Dev. Biol. 53: $217-240$.

Ready, D.F., A. Tomlinson, and R.M. Lebovitz. 1986. Building an ommatidium: Geometry and genes. In Development of order in the visual system (ed. S.R. Hilfer and J.B. Sheffield), pp. 97-125. Springer-Verlag, New York.

Rosenberg, A.H., B.N. Lade, D.-S. Chui, S.-W. Lin, J.J. Dunn, and F.W. Studier. 1987. Vectors for selective expression of cloned DNAs by T7 RNA polymerase. Gene 56: 125-135.

Rubin, G.M. and A.C. Spradling. 1982. Genetic transformation of Drosophila with transposable element vectors. Science 218: 348-353.

Simon, J.A., C.A. Sutton, R.B. Lobell, R.L. Glaser, and J.T. Lis. 
1985. Determinants of heat shock-induced chromosome puffing. Cell 40: 805-817.

Sorger, P.K. and H.R.B. Pelham. 1988. Yeast heat shock factor is an essential DNA-binding protein that exhibits temperature-dependent phosphorylation. Cell 54: 855-864.

Stark, W.S. and R. Sapp. 1989. Ultrastructure of the ocellar visual system in normal and mutant Drosophila melanogaster. I. Neurogenet. 5: 127-153.

Stark, W.S., K. Srivastava, S.D. Carlson, and M.B. Garment. 1984. Characteristics of none, a mutant with no ocelli and narrow eyes. Dros. Inf. Serv. 60: 191-193.

Studier, F.W. and B.A. Moffatt. 1986. Use of bacteriophage T7 RNA polymerase to direct selective high-level expression of cloned genes. J. Mol. Biol. 189: 113-130.

Tautz, D. and C. Pfeifle. 1989. A non-radioactive in situ hybridization method for the localization of specific RNAs in Drosophila embryos reveals translational control of the segmentation gene hunchback. Chromosoma 98: 81-85.

Tix, S., J.S. Minden, and G.M. Technau. 1989. Pre-existing neuronal pathways in the developing optic lobes of Drosophila. Development 105: 739-746.

Tomlinson, A. 1985. The cellular dynamics of pattern formation in the eye of Drosophila. J. Embryol. Exp. Morphol. 89: 313-331.

- 1988. Cellular interactions in the developing Drosophila eye. Development 104: 183-193.

Tomlinson, A. and D.F. Ready. 1986. sevenless: A cell-specific homeotic mutation of the Drosophila eye. Science 231: 400 402.

1987. Neuronal differentiation in the Drosophila ommatidium. Dev. Biol. 120: 366-376.

Tomlinson, A., B.E. Kimmel, and G.M. Rubin. 1988. rough, a Drosophila homeobox gene required in photoreceptors R2 and R5 for inductive interactions in the developing eye. Cell 55: 771-784.

Van Vactor, D., Jr., D.E. Krantz, R. Reinke, and S.L. Zipursky. 1988. Analysis of mutants in chaoptin, a photoreceptor cellspecific glycoprotein in Drosophila, reveals its role in cellular morphogenesis. Cell 52: 281-290.

Zipursky, S.L., T.R. Venkatesh, D.B. Teplow, and S. Benzer. 1984. Neuronal development in the Drosophila retina: Monoclonal antibodies as molecular probes. Cell 36: 15-26.

Zuker, C.S., A.F. Cowman, and G.M. Rubin. 1985. Isolation and structure of a rhodopsin gene from D. melanogaster. Cell 40: $851-858$. 


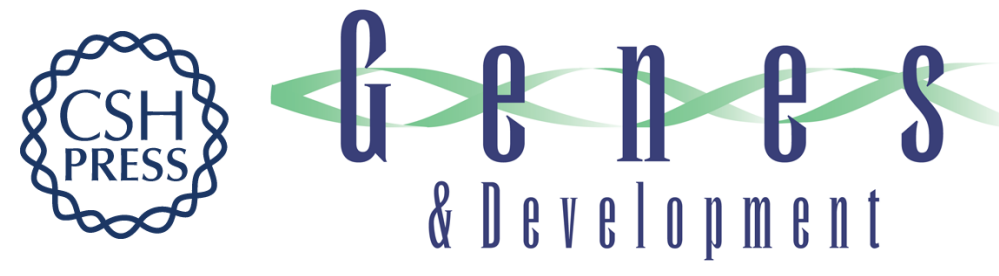

\section{Glass encodes a site-specific DNA-binding protein that is regulated in response to positional signals in the developing Drosophila eye.}

K Moses and G M Rubin

Genes Dev. 1991, 5:

Access the most recent version at doi:10.1101/gad.5.4.583

References This article cites 49 articles, 16 of which can be accessed free at:

http://genesdev.cshlp.org/content/5/4/583.full.html\#ref-list-1

License

Email Alerting

Service

Receive free email alerts when new articles cite this article - sign up in the box at the top right corner of the article or click here.

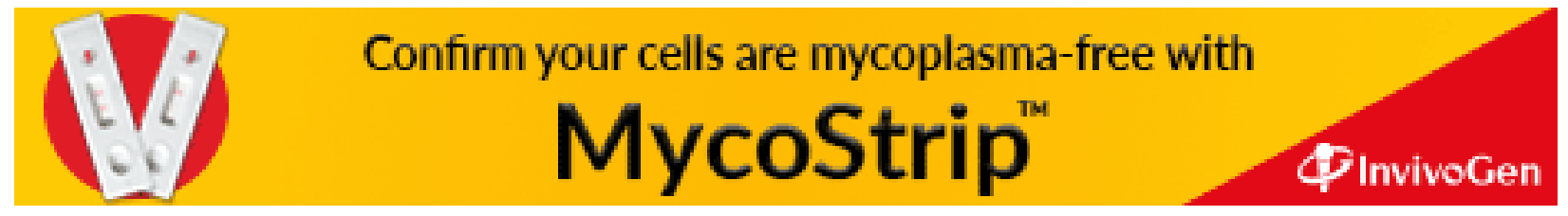

